\title{
The Records Management Capacity Assessment System (RMCAS) as a tool for program development at the Turkish Red Crescent Society
}

\author{
Özgür Külcüa ${ }^{a} *$, Hande Uzun Külcü ${ }^{b}$ \\ ${ }^{a}$ Hacettepe University, Department of Information Studies, Beytepe Campus, 06800 Cankaya Ankara, Turkey \\ ${ }^{\mathrm{b}}$ Turkish Red Crescent Society, Communication and Archive Unit, Turkey
}

\section{A R T I C L E I N F O}

Article history:

\section{Keywords:}

Records management

Program development

Capacity assessment

Capacity analysis

Records Management Capacity Assessment

System (RMCAS)

Turkish Red Crescent Society

\begin{abstract}
A B S T R A C T
The evaluation of institutional condition is regarded as a crucial factor in creating effective and efficient records management systems. In addition, as part of program development studies, national and international programs' best practices and guidelines need to be investigated. In this study, the Records Management Capacity Assessment System (RMCAS) is evaluated and some practical examples that could be used for developing records management programs are examined. The basic aim of this study is to identify records management practices and to provide an example to institutions that are in the stage of program development. The results of an RMCAS analysis of practices of the Turkish Red Crescent Society (TRCS) are also presented in this study.
\end{abstract}

(c) 2009 Elsevier Ltd. All rights reserved.

\section{Introduction}

Records managers are required to assess the extent to which their studies satisfy the needs of an institution. These assessments are based not only on institutional requirements, but also on national and international standards. The first stage of the assessment is comprised of defining the institutional structure and operation. Identification of the internal and external conditions that have an effect on the institution's work and operations is then necessary. Subsequent to this identification, the current records system should be evaluated by taking all of these conditions into consideration. The appropriate techniques for each records management function are expected to be used or developed in the evaluation of the records management system (Information Management Planning, 2005; Shepherd \& Geoffrey, 2003). The field surveys may be conducted either in accordance with preliminary studies of the institution or by making use of previously developed techniques.

The development of records management programs in line with institutional requirements, national and international regulations, and the expectations of parties involved with the institution's services are considered to be highly significant. Within this framework, multifaceted approaches should be adopted in program

\footnotetext{
* Corresponding author.

Tel.: +90 31229782 00/282 88 30/505 3715394 (mobile).

E-mail addresses: ozgurkulcu@gmail.com, kulcu@hacettepe.edu.tr (Ö. Külcü), handeu@kizilay.org.tr, handeuzun@yahoo.com (H.U. Külcü).

URL: http://yunus.hacettepe.edu.tr/ kulcu (Ö. Külcü).
}

development for the records that are used for official communication within the institution and that have the function of verification, and, if need be, previous examples of the developed applications and analyses should be used (Williams, 2002). Records management programs are considered to be able to satisfy the institution's internal and external needs by means of surveys to be conducted through both the examples of applications. Program development in records management rests substantially on institutional analyses. The administrative and legal conditions of every work process affecting the records procedures in the institution should be evaluated in the analyses to be conducted. The assessment of the international standards and the application samples that are developed is considered to be feasible through analyzation of the administrative and legal processes that have an effect on the institutional records procedures and through the development of institutional records management programs (Pember, 2006, p. 22; Shepherd \& Geoffrey, 2003, pp. 30-31; Spratt, 2004, p. 8; Zawiyah \& Chell, 2002, p. 55).

\section{The program development studies on records management}

The primary objective of records management studies has long been to dispose of the growing number of printed records and to relieve the shrinkage of storage areas. The possibilities of access are considered to become more efficient accordingly. Today, however, concepts like the authenticity and reliability of records are being discussed even more frequently, along with the electronic environment. The information required for institutional decisions 
is provided by the records containing the previously run applications and resolutions. Likewise, content analyses conducted for the development of institutional applications are based on the records that comprise the recorded information. These developments necessitate elaboration on records management from a wider perspective (Williams, 2002). The management of the recorded information is described as the management of the information which is recorded in the working process and in a reproducible form (Külcü, 2005; Penn, Mordel, \& Pennix, 1994). It is necessary to develop the policies defining the actions to be taken by the records management applications, the scope of which is everexpanding; to regulate the procedures through which these policies are to be implemented; and to determine how the applications are to be supervised and evaluated (Williams, 2002).

Capacity assessment in records management has been a center of interest for many institutions in different fields and a number of studies have been conducted in related areas. These studies not only enabled the evaluation of institutional records systems, but were also used in the development of general applications and programs on capacity assessment in records management.

\section{The practices on the development of records management systems}

Examples of studies conducted on the development of records management systems in various institutions are presented below in chronological order.

In a doctoral study on the capacity assessment in records management conducted by Hutchinson at La Verne University in 1996 (Hutchinson, 1996), information and records management applications in the public institutions of California are discussed comprehensively. Within the scope of the 58 public institutions on which the study was based, the records management programs are retrospectively elaborated on, the problems encountered in the ongoing programs are described, and the practices, standards, and activities achieved in the development of the programs are touched upon.

Among the data collected during the study, it is remarkable that $92.86 \%$ of the examined institutions have a records management manual. According to further results, more than half of the total number of these institutions have micro records management programs (57) while 50\% have vital records preservation programs and $42.68 \%$ have form management programs. The institutions regard the records retention charts to be the most significant element of their current records management programs. Other elements specified as significant are access to information, security of vital records, file management, integrated technology applications, records center operations, form and report management, preservation of historical records, and correspondence management.

In a master's study conducted by O'Brien (1999) at Royal Roads University, staff members who run the records procedures at the 23 institutions constituting the sample stated that the workload in records management systems is most notably at top level intensity at the out-of-unit records centers, those storage centers where the records are half-active, at the rate of $96 \%$. The other fields where the workload is stated to be heavy are as follows: filing systems (91\%), access services (87\%), retention plans (83\%), software for information and records systems (78\%) and design of the access tools (65\%), vital records planning (65\%), disaster preparedness planning (61\%), cost analyses (52\%), project management (48\%), performance analysis (43\%), micrographs (43\%), risk analyses (35\%), supervision (30\%), work flow design (26\%), reprography or copying (18\%), and form management (4\%).

In a study conducted by Williams (2002), materialized with the support of the Enterprise Content Management Group attached to the Association of International Information Management, content analyses of the records management applications of certain businesses providing services in different fields in the United States are conducted (Williams, 2002). The records management capacities of the institutions are presented and the areas in which problems are encountered are identified. According to the study, the most problematic area in terms of records management within enterprises in the United States is security (68\%), and $53 \%$ of the studied institutions do not have an e-records management application. However, $61 \%$ of the institutions stated that they have a retention plan for their e-mail system and 63\% reported that they keep and dispose of their records in accordance with records retention plans (Williams, 2002).

In a study conducted in Mozambique, the relationship between records management applications and sustainable development plans is dwelt upon and it is concluded that provision of efficiency in the field of public administration depends to a large extent upon effective records management applications (Chibambo, 2003).

In 2005, a 75-page guidebook entitled Information Management Planning was prepared as a result of detailed analyses and assessments of public institutions attached to the provincial government of Alberta, Canada. The development of records management programs within the institutions is described stage-by-stage in this guidebook, which includes detailed information in the following categories: creation of a planning group for the development of records management programs; specification of institutional mission and vision; presentation of the existing values; description of the deficiencies, problems, solutions, and priorities; and plan development (Information Management Planning, 2005).

In the doctoral study conducted by Munro (2005) for the Faculty of Law of Toronto University, electronic records are elaborated on and assessed within the framework of the risk factors created by Internet service providers, personal information, and legal access issues.

In 2005, the relationship between the applications of records management and quality system documentation in universities is examined and a quality record management model for the Turkish Higher Education System is developed in the doctoral study conducted by Külcü in Turkey (Külcü, 2005). In another study carried out in 2008, a comprehensive field survey is conducted on e-records management applications within e-government and its results are evaluated within the scope of the InterPARES III Project (Külcü, 2008).

\section{Records management capacity assessment system (RMCAS)}

RMCAS was developed as part of the International Records Management Trust's Evidence-Based Governance in the Electronic Age Project, which was been funded by the World Bank. To develop RMCAS, the International Records Management Trust (IRMT) drew upon previous research that demonstrated the relationship between records management, financial management, and accountability. In developing RMCAS, the IRMT's aim has been to not only provide a means of evaluating whether the infrastructure of laws, organizational structures, policies, procedures, and facilities exists to manage records effectively, but also to provide a methodology with which to identify problems and begin to plan solutions. RMCAS has been field-tested by government agencies in Botswana, Kenya, Ghana, India, Malawi, Singapore, South Africa, and Yap, a state of the Federated States of Micronesia. Peer reviews were also carried out in Canada, Iceland, and New Zealand (Demp, 2004).

RMCAS is a three-part tool that maps capacity levels to the principles and statements of good practice in records management. It is comprised of a data-gathering element, a diagnostic model, and a database of capacity-building resources for records 
and information management. Information is gathered through structured interview questions for stakeholders and fed into the diagnostic model to produce reports representing strengths and weaknesses in records management infrastructure and systems, or, in other words, an assessment. Graphical representations highlight areas where capacity-building is required in relation to the life cycle or continuum of records, from their creation and capture through their active life to their ultimate preservation in archives or their destruction. It also highlights areas where capacity-building may be needed in relation to the management environment of policies, procedures, skills, and resources, in which records are managed (Griffin, 2004).

In summary, RMCAS is comprised of three components:

- a data-gathering element consisting of assessment questions in structured sequences;

- a diagnostic model which maps the data gathered against statements of good practice and capacity levels;

- and a database of training and capacity-building resources for records and information management.

RMCAS is designed to be useful in countries in which resource constraints demand practical and realistic solutions. Currently, RMCAS contains assessment modules on financial, human resource, and legal and judicial records and information systems. All modules can be applied to both paper and digital records and can be used to assess the relationship between paper and electronic recordkeeping systems. In particular, RMCAS can be used to determine whether the existing infrastructure, control systems, resources, and capacity are adequate to capture and preserve records that are created in the electronic environment. RMCAS measures data gathered by means of the assessment questions against requirements of good practice, as defined by recognized standards or models, including ISO 15489, MOREQ, and Canada's Information Management Capacity Check (Demp, 2004; Griffin, 2004; RMCAS User Guide, 2005).

\subsection{RMCAS organizational environment elements}

The organizational environment elements comprise the larger management and user context in which business and records functions take place and are mapped to statements of good practice. These elements include:

- Laws, policies and procedures: Rules that prescribe how records management and business functions must or should be carried out within the organization.

- ICT-RM integration: How extensively information and communication technology is used to support records management processes and records throughout their lifecycles.

- Business function-RM integration: How thoroughly records management is integrated with normal business functions.

- Resources and training: Whether there is a sufficient budget for a records management program, enough trained staff to carry out all required tasks, proper facilities and equipment, and sufficient supplies. Includes training and support for records creators and users.

- Records management program management: Whether there is an awareness of records management and its centrality to carrying out the business function of the organization through planned administration of records management functions and resources.

- Awareness and ownership: Whether there is an awareness of records management in the organization and senior management buy-in or support for records management program and initiatives. Indicates staff willingness and ability to integrate records management activities in business functions.

\subsection{Records management process elements}

Each element represents a single step in the records management process. The process elements are based on the ISO 15489 standard in records management. "Process" is also used as a separate element in its own right when an activity relates to the entire spectrum of the processes listed. Process elements include:

- Records capture and registration: Allocation of explicit metadata embedded in, attached to, or associated with the specific record regardless of format, arranged in a logical structure or sequence which facilitates subsequent use and reference and provides evidence of the existence of records in a records system. Capture and registration may occur simultaneously with records creation.

- Records classification: Records classification systems reflect business activities and provide linkages between individual documents to provide continuous documentation of activity. Classification is consistent and assists in records retrieval, security and access, and determination of retention periods and disposition actions for records. May occur at the time of records capture.

- Records storage and preservation: Records are stored on media that ensures their reliability, authenticity, and usability for as long as they are needed in proper storage conditions, which protect against unauthorized access, loss or destruction, and theft and disaster.

- Records access: There are formal guidelines to regulate who is permitted access to what records and under what circumstances. The access environment may include privacy, security, freedom of information, and archival legislation. Access may relate to the monitoring of user permissions and functional job responsibilities.

- Records tracking: The tracking of movements and use of records is required to identify outstanding actions, facilitate records retrieval, prevent loss of records, monitor records use, maintain an auditable trail of records transactions, and identify the operational origins of individual records in which systems may have been amalgamated or migrated.

- Records disposition: Disposition authorities, such as records retention schedules, govern the removal of records from operational systems in a systematic and routine basis in the course of normal business activity. Disposition may encompass physical destruction, retention for a further period within the business unit, transfer to an appropriate storage area or medium under organizational control, transfer to a third party storage facility, or transfer to an organizational or external archive (Demp, 2004; Griffin, 2004; RMCAS User Guide, 2005).

The concepts and terminology and, in particular, the good practice statements used in RMCAS are based upon the International Standards Organization's International Standard on Records Management (ISO 15489) issued in 2001, the European Commission's Model Requirements for the Management of Electronic Records (MoReq), and the National Archives of Canada's Information Management Capacity Check published in 2002 (RMCAS User Guide, 2005).

\section{About the Turkish Red Crescent Society (TRCS)}

The TRCS was founded on 11 June 1868. It still continues its activities with profound attachment to the "basic principles of the International Red Crescent and Red Cross; namely, humanity, impartiality, neutrality, independence, voluntary service, unity and universality" (Kızılay, 2006). The mission of the TRCS is "to provide relief to the vulnerable and those in need by mobilizing the power and resources of the community to protect human 
dignity anytime, anywhere, under any conditions and to support the enhancement of the community's capacity to cope with disasters." Providing the services to which the institution is deeply attached as quickly and effectively as possible is one of the most important missions of the TRCS. In terms of providing services effectively and on time, communicative activities come into prominence. At this juncture, records procedures are indispensably significant for internal communication, as well as for communication with the proximate and distant surroundings for which the TRCS is liable to provide services.

\section{RMCAS application in the Turkish Red Crescent Society}

The aim of RMCAS application is to define the conditions for records management applications within the Turkish Red Crescent Society. It is considered to be important for the institution, which do not have enough experience in the field, to analyze its system within the scope of national and international expectations. RMCAS is a significant tool for the definition of the records management conditions of the TRCS. RMCAS was administered as a research technique based on descriptive methods in the TRCS. It is composed of three parts. In the first part, comprehensive questions aimed at analyzing the current system are addressed. RMCAS analyzes the supplied data in accordance with the international regulations in the second part, and the system determines whether the prospective application is carried out in the institution as per the related data in the final part.

The scope of the study includes 22 administrative and coordinative units that are attached to the Directorate General of the TRCS and its branches across the country, blood centers, logistics department, Disaster Operation Center (DOC), and the Afyon Mineral Water Plant. The sample questionnaires and analyses provided by RMCAS were provided to the administrators and staff members of the TRCS's Directorate of Human Resources and the Directorate of Communications and Archives.

The preliminary study demonstrated that the samples of the analyses, which were prepared by taking legal conditions, financial issues, and units of human resources into consideration, may be used effectively for evaluating the current condition of the records procedures in the Directorate of Human Resources of the TRCS. The Directorate of Communications and Archives, which is the second unit upon which RMCAS analyses were conducted, directs the correspondence within all the units and departments of the general-directorates attached to the TRCS and with the public, as well as the records traffic in the TRCS. This Directorate was chosen as the sample for RMCAS due to the scope and content of its work.

\subsection{The results of RMCAS application in the Turkish Red Crescent} Society

A general evaluation of the data demonstrates that the staff members dealing with the records procedures are distributed evenly throughout the institution; however, serious training problems are encountered. While there are fewer problems in the central units, problems in records management applications are more prevalent in the blood centers and the branch offices. Likewise, more problems are encountered in the branch offices in terms of communication and coordination of records procedures than are encountered in the central units. Even though the TRCS published a manual to describe the methods to follow for the in-house records procedures, the rate of referral to this document is below $50 \%$. This shows that certain practices of in-house records procedures, namely seminars, certificate programs, and so on, should be generalized. Problems are observed in the transmission of the administrative and legal regulations developed within the TRCS to the related units, as well. This finding shows that the potential for in-house communication should be further developed. Another source of the problems encountered in the records procedures is the non-use of electronic environment, as stated by the staff members of the institution themselves. The lack of redundant records destruction on time is also among the significant records problems in the institution.

According to the results of the analysis carried out in the TRCS's Directorate of Communications and Archives, the lack of defining the access restrictions to records clearly; the lack of using electronic access tools; the lack of defining the conditions of records retention and access restrictions individually in current, partially current, and noncurrent periods; and the lack of taking the required measures sufficiently so as to prevent unauthorized people's access to the records in the said unit should all be regarded as significant problems. The increased use of electronic environment in the records procedures is considered to be among the priority areas. The results of the analysis conducted in the TRCS's Directorate of Human Resources reveal that all staff members should have access to the documentation within the scope of records procedures and that performance assessment guides should be documented and kept up-to-date and accessible in this unit. It is necessary to keep the forms guiding the records creation process in locations that are accessible for the related staff members. Supervisory mechanisms should be operated for records procedures within the unit. Problems are also encountered in the provision of the access of related staff members to the administrative and legal documents on time during the practices of the unit. There are malfunctions in the unit's management information system.

As per the findings of the analysis carried out within the TRCS and based on RMCAS, the following suggestions should be taken into consideration:

1. It would be beneficial to define the institutional information and records management system, in terms of the development of the current records and archive system, in line with national and international conditions by taking institutional needs into consideration.

2. The results of the RMCAS analysis show that there is a need for more systematic and intensive training activities for the staff members who run the records procedures of the TRCS.

3. Due effort should be exerted to eliminate the problems that arise from running similar procedures in units with different applications.

4. The lack of records disposition on time within the institution is considered to be a serious problem.

5. The electronic records management programs should be suitable for modular use, versatile and structured to enable access at defined levels for meeting future needs. It is important to transfer all of the information and records procedures within the institution to the electronic environment, and in this respect, to meet the requirements for the necessary digital certificates and signatures.

6. It is necessary to define the staff members who shall access the records and the authority with which they shall be provided the access within the TRCS more clearly in the regulations.

7. The retention plans developed for the records in the current, partially current, and noncurrent periods should be put into practice with due attention, as well. International standards, namely TWAIN and ISIS, and PDF and TIFF formats should be used for the transfer of the records procedures into the electronic environment within the institution.

8. In the selection of electronic systems, flexible models that are suitable for multithreading, compatible with HTML and XML standards, and convenient for add-ons should be preferred.

9. Distribution of authority and tasks for the records procedures should be set on a legal basis in the institution. Mechanisms for 
supervising the regular operation of the records and archive system should be defined and operated periodically.

10. The possibility of storage should be provided where easy access to the records is a primary concern and where preservation and security conditions are satisfied.

11. Disaster preparedness plans for the records procedures should be reviewed and the records to be primarily recovered, defined at various levels, should be listed.

It is expected that the RMCAS applications carried out in the TRCS will serve as a guide for other institutions aspiring to develop records management programs, identify the existing problems of records procedures and their sources, and search for the solutions to these problems.

\section{References}

Chibambo, M. L. N. (2003). Records management: the key to good governance and sustainable development. In XVII Biennial Eastern and Southern Africa regional of branch of the international council on archives (ESARBICA) general conference on archives, July 22-26, 2003. Maputo, Mozambique: Society and Good Governance. http://www.ahm.uem.mz/esarbic/docs/marion.pdf. Accessed December 2007

Demp, S. (2004). An introduction to Records Management Capacity Assessment System (RMCAS). Esarbicas Newsletter, 8-13.

Griffin, A. (2004). Records management capacity assessment system (RMCAS) Archival Science, 4, 71-97.

Hutchinson, B. V. (1996). Records and information management in California Counties Unpublished doctoral dissertation, University of California La Verne School of Organizational Management Department of Public Administration.

Information Management Planning (2005). Government of Alberta Information Management Branch. http://www.im.gov.ab.ca/publications/pdf/IMPlanningGuide. pdf. Accessed August 2008

ISO 15489-1. (2001). International Records Management Standard. Switzerland: ISO/TC 46 Technical Committee, pp. 1-11. http://www.arxiversvalecians.org/ document/ISO_TR_15489-1pdf. Accessed February 2006.

Kızılay (2006). Türkiye Kızılay Derneği. http://www.kizilay.org.tr/index.php? menu1=1. Accessed February 2006

Külcü, Ö. (2005). Kamu Üniversitelerinde Kalite Yönetimi ve Kalite Sistem Dokümantasyonu Çerçevesinde Belge Yönetimi. Unpublished doctoral thesis, Hacettepe University, Ankara, Turkey.

Külcü, Ö. (2008). Evolution of the e-records management practices in terms of egovernment, the issues and expectations, reflections from Turkey. In InterPARES
3 Project 2nd international summit, 28-30 April 2008. Oslo, Norway: Det Norske Veritaas.

Munro, K. D. M. (2005). Electronic records as a corporate risk: Internet service providers, personal information and lawful access. Unpublished doctoral dissertation, University of Toronto, Graduate Department of Faculty of Law.

O'Brien, J. J. (1999). Factors for influence organizational context and leadership in recorded information management. Unpublished master's thesis, Royal Roads University. Master of Arts in Leadership and Training.

Pember, M. (2006). Sorting out the standards: what every records and information professional should know. Records Management Journal, 16(1), 21-31.

Penn, I. A., Mordel, A., \& Pennix, G. (1994). Record management handbook. Gower: Kelvin Smith.

Records Management Capacity Assessment System: User Guide. (2005). International Records Management Trust. Version 1.4. http://www.nationalarchives. gov.uk/rmcas/documentation/rmcas_user_guide.pdf. Accessed September 2008

Shepherd, E., \& Geoffrey, Y. (2003). Managing records a handbook of principles and practices. London: Facet Publishing.

Spratt, R. (2004). Records management: The next ten years. RDIMS (Records, Documents and Image Management Systems). Canadian Federal Government Shared System Initiative. https://www.rdims.com/Documents/WhitePaper-Records Management-The NextTenYears.doc. Accessed November 2006.

Williams, R. F. (2002). Realizing the need and putting the key components in place to getting it right in records management. MD: AIIM International.

Zawiyah, M. Y., \& Chell, R. W. (2002). Towards a theoretical construct for records management. Records Management Journal, 12(2), 55-64.

Dr. Özgür Külcü is an assistant professor in the Department of Information Management, Faculty of Letters, Hacettepe University, Ankara, Turkey. Previously he worked as a records manager in various public organizations. He is now Director of Team Turkey of InterPARES 3 Project which is International project on the authenticity, reliability and long term protection of electronic records. He wrote his doctorial thesis, Records Management in the Term of Quality Management and Quality System Documentation in Turkish Public Universities, in 2005. He is a lecturer on institutional information and records management at Hacettepe University since 2001. His main research interests are records management, quality management, and quality system documentation, particularly the analysis of institutional administrative systems. His work has been presented at national and international conferences and has been published in several journals.

Hande Uzun Külcü is a communication and records management specialist in Turkish Red Crescent Society since 2005. She is a Master of Science degree from Hacettepe University about instructional information and records management. She has been already some scholarly studies and consultant activities on information system design and information capacity assessment. Her special interests are organizing civil society activities, designing information system architecture, records and archival system planning. 